Geografia e Ordenamento do Território, Revista Electrónica

Centro de Estudos de Geografia e Ordenamento do Território

http://cegot.org

ISSN: 2182-1267

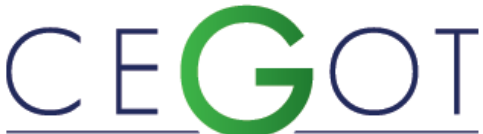

Centro de Estudos de Geografia e Ordenamento do Território

\author{
SANCHO, ALTAIR \\ Universidade Federal de Juiz de Fora, \\ Departamento de Turismo, Laboratório OPETur - \\ Organização e Produção do Espaço e Turismo \\ Rua Antônio Carlos Saraiva, 240/502. Bairro: Cascatinha, \\ 36033345, Juiz de Fora, MG, Brasil \\ altair.sancho@ufjf.edu.br
}

\title{
Ordenamento territorial e áreas protegidas: um olhar sobre o processo de criação do Parque Nacional da Serra do Cipó, MG
}

Territorial planning and protected areas: a look on process of creation the National Park of Serra do Cipó, MG

Referência: Altair, Sancho (2017). Ordenamento territorial e áreas protegidas: um olhar sobre o processo de criação do Parque Nacional da Serra do Cipó, MG. Revista de Geografia e Ordenamento do Território (GOT), n.o 12 (dezembro). Centro de Estudos de Geografia e Ordenamento do Território, p. 309-333, dx.doi.org/10.17127/got/2017.12.014

\section{RESUMO}

A interpretação das áreas protegidas sob o viés conceitual do ordenamento territorial sugere reconhecer, de imediato, a tentativa do Estado de instituir certa visão/ordem de proteção ambiental. Ao mesmo tempo, os debates teóricos mais recentes sobre ordenamento sugerem também contemplar a multiplicidade de forças que se conjugam, de formas distintas, nos territórios protegidos e os desafios que aí se apresentam à consolidação de processos de ordenamento mais democráticos e alinhados às demandas locais. Inspirados nestas ideias, o presente artigo tem por objetivo compreender o processo de criação do Parque Nacional da Serra do Cipó, MG. Esse esforço de investigação, de caráter fundamentalmente qualitativo, foi orientado por três recursos de pesquisa principais: levantamento bibliográfico, observação participante e entrevistas.

Palavras-chave: Ordenamento Territorial, Áreas Protegidas, Parque, Parque Nacional da Serra do Cipó. 


\section{ABSTRACT}

The interpretation of protected areas under the territorial planning concept suggests to recognize, at first, the attempt of the State to establish certain environmental protections vision/order. At the same time, the recent theoretic discussions about territorial planning suggests also considerate the multiplicity of forces that conjugate themselves, in different ways, in the protected territories and the challenges presented there to consolidation of planning processes that is more democratic and aligned to the local demands. This research, from a qualitative perspective, was guided by three principal methods of research: bibliographical survey, participating observation and interviews.

Key-words: Territorial Planning, Protected Areas, Park, Serra do Cipó National Park.

\section{Introdução}

O processo de criação e gestão de territórios dedicados à conservação de atributos naturais representa um fenômeno de grande complexidade na atualidade, envolvendo não apenas aspectos de conservação de atributos naturais, mas também, aspectos socioculturais, políticos e econômicos. Resultado de uma relação historicamente caracterizada pela tentativa de dominação da natureza pela sociedade, em especial a sociedade ocidental - via separação da ideia e matéria, ciência, técnica, razão e trabalho -, o estabelecimento de áreas naturais protegidas passou a constituir, sobretudo a partir do século XIX, um elemento de reordenamento territorial, com profundas implicações nos processos socioespaciais onde se instala (SANCHO e DEUS, 2015).

No caso da criação de áreas protegidas, como os parques, o ordenamento que aí se substantiva representa, em grande medida, a reprodução das relações de poder objetivas (representadas pela visão do Estado) sobre as relações simbólico-identitárias inerentes às práticas dos diversos grupos sociais residentes nos territórios alvo das políticas de proteção ambiental. E ainda são incipientes as experiências que vão na contramão desse processo. Norteado por uma perspectiva de dissociação ou, pelo menos, de relativo distanciamento entre homem e natureza, o processos de territorialização que se concretiza por meio dos parques ainda não consegue contemplar, efetiva e integralmente, as múltiplas territorialidades coexistentes.

O processo de criação do Parque Nacional da Serra do Cipó é emblemático nesse sentido. Coordenada à época pelo IBDF - Instituto Brasileiro de Desenvolvimento Florestal, essa área 
de proteção foi instituída, em 1984 ${ }^{1}$, através do Decreto n 90.223 de 25/09/1984, abrangendo territórios de quatro municípios - Jaboticatubas, Santana do Riacho, Morro do Pilar e Itambé do Mato Dentro. Sua criação se justificou pela necessidade de proteção da fauna e flora da Cadeia do Espinhaço, e particularmente da Serra do Cipó, devido ao alto grau de endemismo de suas espécies, necessidade de proteção da bacia de captação do rio Cipó e preservação das belezas cênicas da região que vinham sendo ameaçadas por queimadas para a formação de pastos, pelo intensivo extrativismo de plantas ornamentais e de madeira para lenha e produção de carvão.

A criação do PARNASC constituiu, portanto, uma iniciativa essencialmente voltada à proteção da biodiversidade da porção meridional da Serra do Espinhaço, com incidência direta em sua dinâmica socioespacial e nos exercícios de territorialidade precedentes.

Diante desse contexto, o presente artigo tem por objetivo compreender o processo de criação do Parque Nacional da Serra do Cipó, MG. Ancorado em uma perspectiva fundamentalmente qualitativa de investigação, nosso esforço de aproximação dessa realidade envolveu, primeiramente, um aprofundamento teórico sobre as temáticas de áreas protegidas, unidades de conservação ${ }^{2}$ e ordenamento territorial. Foram, nesse caso, realizadas pesquisas bibliográficas em livros, artigos científicos, teses e dissertações, nacionais e internacionais.

Em seguida, as investigações sobre o processo de criação do PARNASC contemplaram o reconhecimento das justificativas técnicas de criação dessa área protegida e a forma como tal processo foi conduzido, em termos de adoção de estratégias voltadas à sensibilização e envolvimento social. Procuramos também compreender a visão de interlocutores de órgãos ambientais e moradores que participaram direta ou indiretamente da criação do PARNASC. Para tanto, além de levantamento bibliográfico, realizamos ainda pesquisas documentais no IEF/MG, IBAMA, ICMBio e na sede do PARNASC. Além disso, estabelecemos conversas e

\footnotetext{
${ }^{1}$ Cumpre mencionar que em 1984 ocorreu o processo de federalização desta Unidade de Conservação, então Parque Estadual da Serra do Cipó, criado em 1975, no âmbito da Lei Estadual do Estado de Minas Gerais n. 6.605 de 14/07/75.

${ }^{2}$ Cumpre mencionar que, à época da criação do Parque na Serra do Cipó, o termo "unidade de conservação" ainda não havia sido instituído no arcabouço legal brasileiro, fato que somente ocorreu com a criação do Sistema Nacional de Unidades de Conservação (Lei 9.985/2000), em 2000. Como o período de criação do referido parque é anterior à criação do SNUC, optamos por adotar a nomenclatura "área protegida".
} 
entrevistas semiestruturadas com ex-gestores e analistas ambientais do PARNASC e, ainda, moradores que vivenciaram diretamente seu processo de criação. Trata-se, como apontam Corrêa e Guiraud (2009, p. 683) de "recuperar elementos da história de vida, sem, no entanto, fazer história de vida, construir biografia". Dessa maneira, os relatos e depoimentos orais foram tidos como uma possibilidade de elucidar outros elementos e visões, especialmente aqueles "não oficiais", sobre a história de criação do PARNASC, com o intuito de melhor compreender tal processo.

\section{Ordenamento territorial: aproximações conceituais e desafios que se apresentam na contemporaneidade}

O termo "ordenamento territorial" nos remete à ideia de um sentido, um rumo, uma direção que orienta a forma como uma sociedade se organiza em determinada porção espacial, para alcançar objetivos específicos. Ordenar o território implica, dessa maneira, em poder, poder de priorizar determinadas concepções de mundo e interesses no âmbito de dada organização social. Esse processo pode ser construído a partir de uma perspectiva mais centralizada, ancorada em um sentido único de ordem e direção, ou a partir de uma perspectiva mais descentralizada, que privilegia escalas regionais e locais, o que, longe de significar ou almejar autossuficiência, visa contemplar os valores, práticas e saberes presentes no território e estimular as capacidades locais de gestão territorial, num constante diálogo com níveis e propostas mais abrangentes (macroestruturais) de ordenamento ${ }^{3}$.

A prática de ordenar o território é uma ação percebida já nos primeiros assentamentos humanos, onde é possível reconhecer objetivos e normas de uso comuns. Segundo Santos (1997 apud MELO, 2010), as primeiras informações históricas sobre organização espacial descrevem ideias embrionárias ligadas à prática da agricultura e da pesca, sempre se

\footnotetext{
${ }^{3}$ Nesta investigação, optamos por seguir a linha conceitual sugerida por Haesbaert, que define território "a partir da imbricação de múltiplas relações de poder, do poder mais material das relações econômico-políticas ao poder mais simbólico das relações de ordem mais estritamente cultural" (HAESBAERT, 2004, p. 79)
} 
considerando os aspectos físico-ambientais, como topografia, microclima e qualidade dos solos, numa relação mais condicionada ao tempo e aos ritmos da natureza.

Contudo, a noção de ordenamento territorial sob a ótica institucional, diretamente associada ao poder do Estado e aos seus objetivos de controle e desenvolvimento do território, tem origem no contexto histórico pós-revolução francesa. A concepção de ordenamento territorial (amenagement du territoire) emerge na França, tanto como artifício para consolidar o projeto ideológico de nação em prol da afirmação de uma identidade nacional, quanto como estratégia de planejamento regional, fornecendo ao Estado condições de conhecer, coordenar e administrar seu território, por meio de sua divisão. Essa divisão regional em unidades de planejamento era determinada por pressupostos físicos (as bacias hidrográficas, por exemplo) e em características de ordem administrativa e econômica (interesses e prioridades estratégicas, produção agrícola, mineração, etc.), ideia aliás, ainda presente no conceito de região (SANTA INEZ, 2004).

Segundo Peres e Chiquito (2012), no contexto europeu pós-segunda guerra, essa perspectiva do ordenamento territorial voltou a compor a agenda política. A Charte de l'Amenagement (1953) consolida, então, uma concepção de ordenamento do território na França, cujo objetivo reside em "criar condições, através do planejamento, para a valorização, aproveitamento e desenvolvimento do território, por meio da organização racional do espaço e da implantação de equipamentos apropriados, visando a melhoria das condições de vida das populações" (Op. cit., p. 73).

Diretamente centralizada no poder e na visão do Estado (e fazendo alusão à perspectiva ratzeliana de território), essa concepção de ordenamento territorial vai se consagrar e se disseminar por diversos países. Tal ideia privilegia o olhar técnico do planejamento (inacessível à maioria da população, o que muitas vezes o torna "inquestionável") e uma concepção abstrata e racional do espaço, que norteiam a determinação de referenciais e critérios (especialmente geração de riquezas) para a seleção de regiões, setores prioritários e estratégias de gestão e implementação de programas e projetos voltados à promoção do desenvolvimento territorial.

No Brasil, essa lógica essencialmente centralizada no poder do Estado foi reproduzida ao longo de praticamente todo o século XX. Peres e Chiquito (2012) teceram uma análise sobre 
como a perspectiva do ordenamento territorial foi internalizada e conduzida aqui, no âmbito da administração do governo (sobretudo, o federal) desde os anos de 1930. O Brasil passou por momentos em que o ordenamento territorial esteve mais associado à ideia de regionalização e ao objetivo de minimização de "desequilíbrios regionais" (em termos econômicos e sociais), e outros, em que o ordenamento se concretizou via polos de crescimento, com predomínio da visão macroeconômica e tendo a cidade como lócus do desenvolvimento.

No cenário contemporâneo, o debate sobre ordenamento territorial adquire novos significados e dimensões quando consideramos a atual dinâmica que passa a permear a realidade dos territórios. Isso porque a prática do ordenamento se vê diante de um conjunto de forças econômicas, políticas e simbólico-culturais que se conjugam, de formas distintas, em cada recorte espacial, acarretando em novos desafios à concepção e implementação de políticas voltadas ao desenvolvimento territorial. Dessa forma, compreender a natureza e o sentido das práticas de ordenamento, bem como as transformações a ele associadas, exige agora um esforço de apreensão desse movimento (des)contínuo de forças presentes e atuantes nos territórios e o reconhecimento de que propostas excessivamente centralizadoras e de conteúdos totalizantes já não são mais viáveis e, tampouco, desejáveis.

Se antes vivíamos sob a guarda e sob os olhares de um Estado central, cujo poder estava clara e fortemente territorializado, resultando em um certo sentido de estabilidade e fixidez, hoje, experimentamos uma vivência de tempo e espaço cada vez mais complexa, multiescalar e fluida, resultante do processo de globalização e do crescimento do intercâmbio de informações, ideias e trocas culturais.

Vale ressaltar que esse novo contexto coloca em xeque a continuidade do controle territorial excessivamente centralizado no Estado-Nação ao conferir maior visibilidade a outras territorialidades, ao mesmo tempo em que abre espaço para a reivindicação de posturas e propostas de gestão mais descentralizadas e participativas. E como aponta Moreira (2006), cada vez mais, a sociedade civil desempenha um papel fundamental nos rumos e na natureza dos arranjos territoriais, de maneira que o poder do Estado não é mais a única fonte de definição das regras e das normas que regulam o espaço. 
Diante dessa nova conjuntura de maior proximidade e relativa abertura para 0 envolvimento da sociedade civil nas esferas decisórias, autores como Becker (2005), Haesbaert (2006), Moreira (2006), Santos (1994, 2006), Deus et al. (2012), Peres e Chiquito (2012), entre tantos outros, discutem acerca dos novos desafios que se apresentam à temática do ordenamento territorial. Todos concordam que o sentido do ordenamento está fundamentado em uma visão macro espacial, mas que precisa articular outras esferas de gestão e escalas existentes em torno de objetivos comuns. Além disso, envolve o fomento à criação de novos espaços de discussão e decisão e incentivo ao comprometimento de diferentes representatividades sociais às discussões sobre temas caros ao desenvolvimento dos territórios.

Haesbaert (2006), por exemplo, aponta que o emaranhado de condições econômicas, políticas e socioculturais que se conjugam atualmente numa porção espacial e as complexas combinações, daí resultantes, dificultam enormemente a construção das políticas de ordenamento territorial - que são, na verdade, sempre e mais do que nunca, políticas de "des-ordenamento". Reconhecendo na contemporaneidade a complexidade inerente a esse processo, cada vez mais des-contínuo e múltiplo - o que significa considerar a dificuldade crescente de construção/imposição de uma ordem específica -, o autor reconhece que o principal objetivo, hoje, da prática do ordenamento territorial é a administração da desordem, a saber: o combate ao acirramento das situações de precarização ou de exclusão socioespacial, o que envolveria a melhoria de condições e meios materiais de vida; ampliação dos espaços democráticos, com a descentralização e envolvimento dos sujeitos sociais nos processos decisórios; reconhecimento de um perspectiva multiescalar imprescindível para se compreender e dar conta das questões e situações concernentes ao processo contemporâneo de ordenamento e, por fim, o fomento ao comprometimento público, o que poderia ser interpretado como valorização da formação cidadã, a partir de uma concepção capaz de integrar as múltiplas identidades.

Já para Deus et al. (2012), a prática do ordenamento envolve: a) um variado espectro de fatores (urbanos, rurais, de localização industrial, vinculados à reforma agrária e à conservação e preservação do meio natural, etc.); b) exige a coordenação de ações em diferentes instâncias (federal, estadual, regional e municipal), por meio de mecanismos de 
articulação interinstitucionais; c) pressupõe uma perspectiva transversal em políticas públicas (incentivos agrícolas, infraestrutura viária e energética, saneamento, urbanização, saúde, educação, geração de emprego, conservação de biodiversidade, reconhecimento de direitos territoriais indígenas, reforma agrária, etc.); d) a criação de novas institucionalidades, como unidades de conservação, comitês de bacia e consórcios intermunicipais e, e) estímulo ao envolvimento da sociedade civil no processo de desenvolvimento territorial.

Essa abrangência pretendida e a ampla diversidade de temas e objetivos atribuídos ao ordenamento indicam, de antemão, seu caráter essencialmente estratégico, enquanto instrumento de planejamento voltado ao estabelecimento de diretrizes e rumos ao desenvolvimento do país, numa perspectiva mais integrada, multiescalar e democrática. Considerando essa característica macro estratégica do ordenamento territorial, o grande desafio à efetiva internalização e implementação dessa prática em todo o território nacional dependerá diretamente do nível de articulação entre as diferentes esferas de gestão, da capacidade de concepção de políticas e planos setoriais transversais e do comprometimento social com sua construção e execução. O alcance de resultados positivos, sobretudo em termos de redução das desigualdades socioespaciais e melhoria da qualidade de vida da população, depende inteiramente do grau de sua aderência à realidade dos territórios. Isso significa dizer que os princípios e diretrizes do ordenamento devem estar alinhados às instâncias estaduais, regionais e locais e ser construídos e assumidos de maneira integrada e participativa, com base no diálogo e na troca de informações e experiências.

\section{Ordenamento Territorial e Áreas Protegidas: algumas considerações sobre o processo de construção de uma ordem de proteção ambiental no Brasil até 1988}

A compreensão do processo de criação do Parque Nacional da Serra do Cipó (PARNASC) exige, primeiramente, um olhar crítico sobre o contexto histórico e político que vigorava no 
Brasil à época de sua instituição, em 1975, inicialmente na figura de Parque Estadual, e posterior federalização, em 1984. Isso porque, nesse período, a criação de parques e outras categorias de áreas protegidas adquiriu centralidade na construção de uma ordem de proteção da natureza no país, enquanto parte de um projeto mais abrangente de cunho nacionalista no âmbito do Estado brasileiro, empreendido com o objetivo de garantir a soberania e a defesa territorial do país.

De antemão, a configuração desta ordem de proteção ambiental pode ser interpretada a partir da conciliação de influências de pensamentos e debates externos com necessidades percebidas e vivenciadas no cenário interno. O sentido do termo influência externa, nesse caso, longe de significar a simples reprodução ou cópia de modelos externos - como bem salienta Medeiros (2003) -, indica, na verdade, o constante papel exercido por linhas de pensamento e interesses externos no processo de construção de um sistema de proteção da natureza no país, seja em termos de reprodução de ideias em determinados momentos, seja como estratégia de reação ou resposta a movimentos e interesses internacionais.

De qualquer forma, não se pode desconsiderar o papel decisivo desempenhado pelo Estado nessa época à frente da condução e coordenação das iniciativas de proteção da natureza, concentrando os esforços de implementação de políticas ambientais com esse objetivo ${ }^{4}$.

Segundo Medeiros et al. (2006), no Brasil, a instituição de áreas protegidas enquanto porções territoriais criadas para a preservação e/ou conservação, pelo ou com o aval do Estado, foi um fenômeno que surgiu ainda no período republicano, especialmente a partir da década de 1930, época da chamada "Revolução de 30", que marcou a transição do país para um contexto de modernização, ancorado nos modelos de industrialização e urbanização, com foco na região sudeste. Nesse contexto de transformações, a questão ambiental e, especificamente, a temática da proteção da natureza, adquiriram então relevância institucional, sob forte influência de acontecimentos e ideias de fora do país. À época, o movimento ambientalista "pró criação" de territórios protegidos ganhava visibilidade no cenário norte-americano como estratégia de reação aos problemas

\footnotetext{
${ }^{4}$ Somente a partir da década de 1990, o Estado passou a adotar uma postura de maior compartilhamento de tais responsabilidades com outros segmentos da sociedade civil, mas o que de maneira alguma reduz sua influência e centralidade nesse processo, o qual remete, diretamente, às questões vinculadas ao ordenamento territorial, vale ressaltar.
} 
ambientais associados ao modelo urbano-industrial, então em franca expansão naquele país. No Brasil, os adeptos desse movimento (que tiveram formação intelectual obtida justamente nos EUA e em países europeus, recebendo portanto grande influência dos debates e ideias ali vigentes) eram pessoas pertencentes à "elite" política, científica e cultural da época e cuja influência resultou na internalização da lógica preservacionista de proteção da natureza na então recente política ambiental do país. Esta concepção de natureza "intocada" (DIEGUES, 2004) e a tendência de exaltação do mundo natural foram incorporadas pelo governo brasileiro em algumas de suas iniciativas de proteção, replicadas, mais tarde, nos primeiros modelos de parques brasileiros.

Nesse primeiro momento, os parques estavam concentrados na região sudeste, situando-se próximos a centros urbanos e constituindo espaços para a pesquisa científica e lazer e, criados também, como estratégia para resguardar áreas de relevante interesse ecológico, dos avanços da civilização moderna em expansão (em especial àquelas abrangidas pela Mata Atlântica, já muito devastada). Como resultado prático dessa perspectiva, no período de 1935-1969, a grande maioria das áreas protegidas criadas foi de proteção integral, referendando essa lógica preservacionista ${ }^{5}$ presente e difundida à época (MEDEIROS, 2003). Contudo, apesar de reconhecer a influência do modelo norte-americano, Medeiros (2003) afirma que a dinâmica particular que aqui se desenvolveu em função das singularidades e contingentes que foram surgindo fez com que o modelo brasileiro não fosse uma cópia estática dos modelos norte-americanos e europeu. O autor cita que, no Brasil, os territórios transformados em parques não se constituíam em "vazios" demográficos, cobertos de

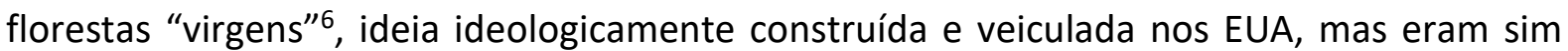

\footnotetext{
${ }^{5}$ Diegues (2004) diferencia duas correntes do movimento de proteção da natureza: a) Preservacionismo: a natureza possui um valor intrínseco, não devendo servir aos interesses exploratórios do ser humano. A essência dessa corrente reverência à natureza no sentido da apreciação estética e espiritual da vida selvagem (wilderness). Busca a preservação de áreas naturais, pelo valor que tem em si mesmas e não nos valores para o uso humano. b) Conservacionismo: vê uma finalidade de utilidade na natureza, para uso do ser humano. 0 movimento dos conservacionistas atribui aos recursos naturais o uso racional. Em sua concepção a natureza é lenta e o processo de manejo pode torná-la eficiente. Essas ideias foram precursoras do conceito de desenvolvimento sustentável.

${ }^{6}$ Para o autor, "o sucesso da iniciativa norte-americana e que a tornou tão popular em outros países, certamente está relacionado com a sua opção de promover a proteção em espaços virtualmente vazios. Virtuais pois, apesar de ali não se encontrarem mais os habitantes originais - que foram dizimados durante o processo de ocupação e colonização sobretudo por ingleses e franceses - as áreas escolhidas só poderiam ser consideradas intocadas do ponto de vista centrado no colonizador ou na sociedade superior, como gostavam de se autoproclamar os desbravadores europeus" (Op. cit., p.140).
} 
habitados por diferentes populações. Isso fez com que essa proposta conceitual inicialmente "importada" sofresse adaptações frente à dinâmica socioespacial aqui existente.

Vale dizer que essas "adaptações", sugeridas pelo autor, significaram a manutenção e incorporação de outras categorias de manejo ao modelo de proteção brasileiro, que permitiam, por exemplo, a presença de populações e exploração "sustentável" de reservas florestais (caminhando para uma vertente conservacionista). No entanto, é preciso deixar claro que as categorias mais restritivas como os parques (foco desta investigação), cujo ideário de proteção pressupõe o impedimento da permanência fixa de pessoas nas áreas criadas, continuaram a referendar a lógica preservacionista, exercendo influência decisiva na construção de uma visão de proteção da natureza no Brasil. Na atualidade, as unidades de conservação de proteção integral ainda reproduzem tal lógica, sustentada por uma vertente do movimento ambientalista e, também, por pesquisadores e especialistas, que afirmam que somente esse tipo de categoria de área protegida consegue, efetivamente, cumprir os objetivos de preservação da biodiversidade, rechaçando, portanto, qualquer tipo de uso que se pretenda controlado e sustentável.

Diante da valorização institucional da temática ambiental, uma nova ordem de proteção se concretiza na Constituição de 1934, quando a natureza foi "oficialmente" reconhecida como patrimônio nacional a ser preservado, sob responsabilidade dos três entes do poder federativo. E, em decorrência disso, diversos instrumentos legais passaram a ser criados com o objetivo de oficializar tal visão de natureza e garantir a imposição de uma lógica específica de proteção, no sentido daquilo que Bourdieu chamou de poder simbólico, reforçando o poder do Estado brasileiro em termos de controle do território e de suas "riquezas" naturais.

Merece destaque a criação do Código Florestal, ainda em 1934, que se tornou o mais importante instrumento da política brasileira de proteção da natureza, à época, reunindo critérios para a proteção dos principais ecossistemas florestais e demais formas de vegetação naturais, além de introduzir a ideia de categorias de manejo em função dos objetivos e finalidades da área criada. Foi a partir da criação do Código Florestal que se 
constituiu um cenário mais propício à criação do primeiro parque nacional do país, o Parque Nacional do Itatiaia, em 1937 (Idem).

Já no período da ditadura militar (1964-1985) - quando houve, à propósito, a instituição do Parque Estadual da Serra do Cipó e sua posterior federalização - a criação de áreas protegidas integrou, como já mencionado, um rol de estratégias de cunho nacionalista no âmbito do Estado brasileiro, empreendidas com o objetivo de garantir a soberania e a defesa territorial do país ${ }^{7}$. No âmbito desse contexto, os rumos da política ambiental preconizaram uma espécie de funcionalização do espaço nacional, segundo três modalidades:

a) regiões dotadas de vocações naturais para inserção no mercado global; b) áreas ricas em recursos genéticos, consideradas natureza a ser preservada como ilhas de conservação ou a serem exploradas de modo que se pretende sustentável; c) áreas residuais economicamente deprimidas, desprovidas de interesses estratégicos para o capital (ACSELRAD, 2001, p. 79).

Nesse cenário, as áreas protegidas assumiram então um papel geopolítico, estratégico sob o ponto de vista do controle territorial, e também econômico. Esse contexto de criação de territórios de domínio público pode, aliás, ser interpretado como uma forma de ratificar a presença do Estado, e de seu poder, numa perspectiva centralizadora e autoritária, o que evidencia, portanto, o forte conteúdo territorial associado à criação de áreas protegidas, estimulado pela centralidade adquirida pelos atributos e riquezas na esfera do Estado.

Esta estrutura centralizada no poder do Estado repercutiu diretamente no viés de ordenamento territorial que se concretizou por meio da criação de áreas protegidas durante o período militar: "up town" ("de cima para baixo"). Tal perspectiva privilegiou visões e objetivos que desconsideravam as populações existentes e suas práticas materiais e simbólicas, orientadas por técnicas cartográficas incapazes de apreender a dinâmica

\footnotetext{
${ }^{7}$ No curso dos debates em torno de uma possível "internacionalização da Amazônia”, por exemplo, os governos militares deram início então a um audacioso projeto de estímulo à ocupação da região amazônica, visando integrá-la ao contexto socioeconômico nacional. Norteados pelo lema "ocupar para não entregar", consolidou-se uma visão de "vazio Amazônico", que desconsiderou e negou aí a existência de mais de 170 nações indígenas, desconhecendo que esse território era terra de ocupação antiga, que abrigava posseiros, garimpeiros, populações quilombolas, entre outros indivíduos e coletividades (SANTANA, 2009).
} 
territorial em questão. Ainda bastante presente nos dias de hoje - na visão de alguns gestores, técnicos ambientais e pesquisadores -, é relevante assinalar que esta lógica de proteção foi responsável por deflagrar inúmeros conflitos territoriais e consolidar uma visão e uma cultura de dicotomia na relação homem e natureza.

Foi justamente no âmbito desse contexto histórico e político-ideológico que o Parque Estadual da Serra da Cipó foi criado. Imbuídos do desafio de se compreender como se efetivou tal processo, algumas questões orientaram a investigação: quais as justificativas de sua criação? qual o viés de ordenamento prevaleceu? Quais sentidos e visões de proteção da natureza foram privilegiados? Houve preocupação em envolver os segmentos sociais diretamente afetados na condução de tal processo?

\section{E inventaram o parque na Serra do Cipó...}

O Parque Nacional da Serra do Cipó (PARNASC) está localizado na região central do Estado de Minas Gerais, a nordeste de Belo Horizonte, mais especificamente na Serra do Cipó, conforme Figura 01, na sequência. Criado por meio do Decreto n 90.223 de 25/09/1984, abrange as áreas de quatro municípios - Jaboticatubas, Santana do Riacho, Morro do Pilar e Itambé do Mato Dentro, totalizando 33.800ha8.

\footnotetext{
${ }^{8} \mathrm{O}$ entorno direto do PARNASC é permeado pela Área de Proteção Ambiental Morro da Pedreira (APAMP), criada em 1990 por meio do Decreto n. 98.891 de 26/01/1990. Um dos objetivos de criação da APAMP foi garantir a proteção do Parque Nacional da Serra do Cipó e o conjunto paisagístico de parte do maciço do Espinhaço.
} 


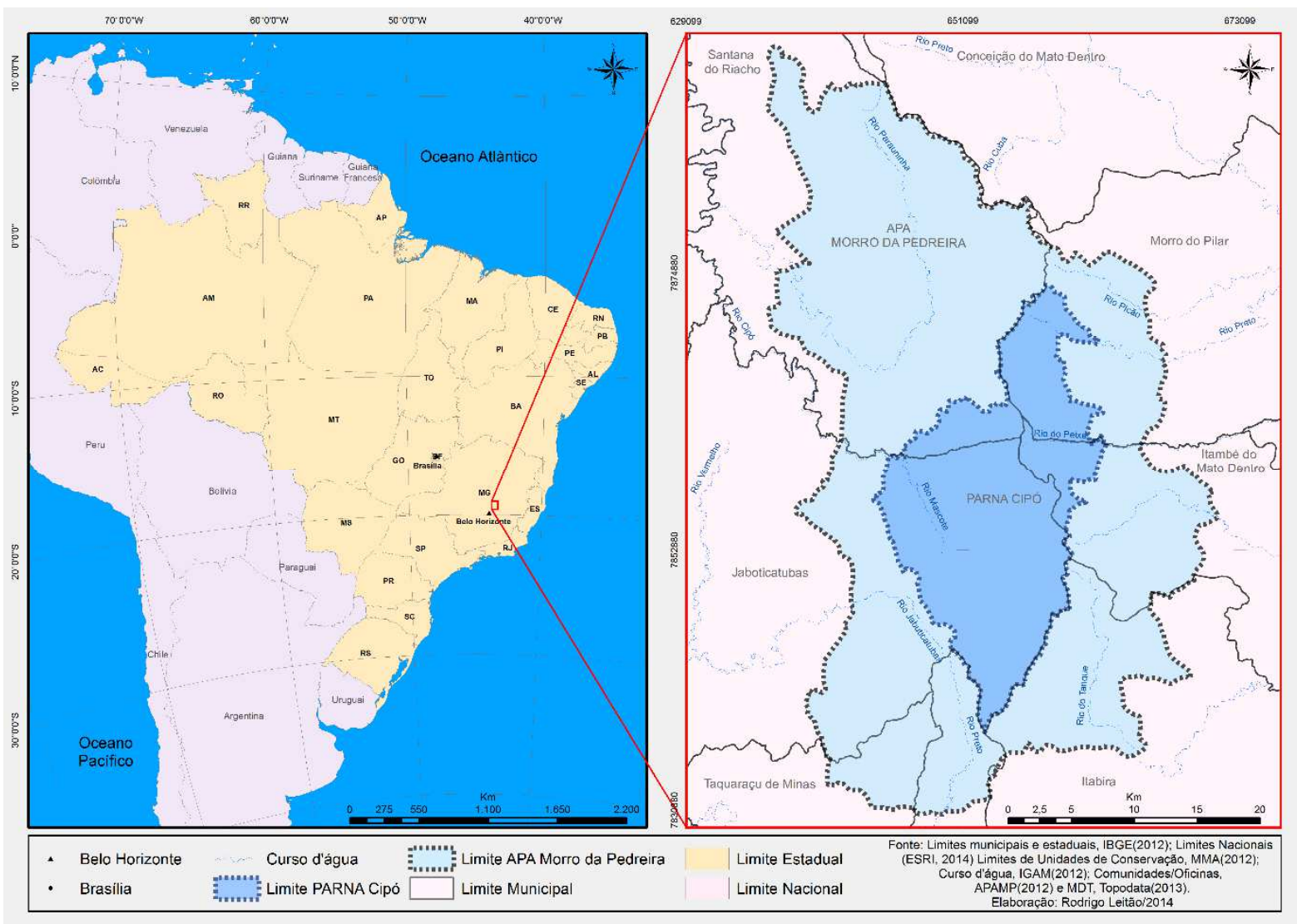

Figura 01- Mapa Localização do Parque Nacional da Serra do Cipó

Segundo o Plano de Manejo do PARNASC (ICMBIO, 2009), as reivindicações de ambientalistas e de pesquisadores (notadamente da Universidade de São Paulo, responsáveis pela maior parte das publicações sobre a biodiversidade da região, à época) marcaram o início do processo de proteção ambiental da Serra do Cipó. O primeiro ato público nessa direção consistiu na instituição da Lei Estadual n. 6.605, de 14 de julho de 1975, que autorizou a criação do então Parque Estadual da Serra do Cipó:

(...) anunciada pelo Governador do Estado durante a reunião anual da Sociedade Brasileira para o Progresso da Ciência de 1976, demonstrando a importância da pressão exercida por cientistas na época. Nesta reunião, o Governador autorizou a realização dos estudos que fundamentariam a criação da área protegida (ICMBIO, 2009, p. 07). 
Além dessa mobilização de pesquisadores visando a proteção das espécies de fauna e flora da região, outros motivos que justificaram a criação do parque na Serra do Cipó foram, como já mencionado, a necessidade de proteção das nascentes que abasteciam a bacia do rio Cipó, o combate a espécies invasoras, os impactos das queimadas, prática do desmatamento, extrativismo de flores e explotação mineral.

De antemão, é importante destacar que interesses mais amplos e "externos" à realidade da região, ou seja, "olhares de fora" vigoraram na decisão pela criação dessa área protegida na Serra do Cipó. Não podemos nos esquecer que, naquela época, ganhava força um movimento de consolidação de uma agenda ambiental global, no âmbito da qual a criação de áreas protegidas assumiu grande centralidade, com repercussões diretas nos modelos de ordenamento territorial de vários países. E, como consequência disso, uma nova ordem ambiental já ganhava impulso, sendo reproduzida em diversos estados brasileiros, com prevalência da adoção do modelo americano de parques, ancorado no estabelecimento de áreas naturais sem a presença de núcleos humanos. No Brasil, a força desse modelo esteve associada à atuação de uma elite política e científica da época, e cujo protagonismo resultou na internalização e privilégio da lógica preservacionista de proteção da Natureza na nascente política ambiental do país. Ao se considerar a realidade de muitas áreas que foram criadas, e da região da Serra do Cipó em particular, percebe-se que a adoção dessa perspectiva de proteção acabou implicando em sobreposições e choques de diferentes e, em muitos casos, contraditórios exercícios de territorialidade, com a ocorrência aí de inúmeras transformações e, mesmo, conflitos territoriais.

Com a autorização "oficial" de criação do Parque Estadual da Serra do Cipó, foram iniciados, em 1978, os estudos para dar continuidade à implantação dessa UC, a cargo, na época, da Fundação Centro Tecnológico de Minas Gerais - $\mathrm{CETEC}^{9}$. Inicialmente, foi realizada a delimitação da área a ser transformada em parque e sua constituição fundiária e benfeitorias para que se pudesse proceder às desapropriações. Após a conclusão do levantamento fundiário, foi assinado, em 1979, um convênio no valor de 30 milhões de cruzeiros, entre o governo do Estado de Minas Gerais e o Ministério da Agricultura, e

\footnotetext{
${ }^{9}$ Os recursos que viabilizaram tais estudos foram oriundos do convênio firmado com o Conselho Nacional de Desenvolvimento Urbano - CNDU, a Empresa Brasileira de Turismo - EMBRATUR e a Secretaria do Patrimônio Histórico e Artístico Nacional - SPHAN (CETEC, 1982).
} 
segundo o qual o governo federal repassaria tal verba para a implantação do Parque. Contudo, tal recurso não foi liberado e sua efetiva implantação ficou, então, comprometida (CETEC, 1982).

Assim, até o início do processo de federalização, o Parque Estadual da Serra do Cipó não possuía estrutura física, funcionários e áreas privadas oficialmente adquiridas pelo Estado, constituindo-se em um verdadeiro "parque de papel". Essa expressão, muito utilizada para caracterizar a situação de outras áreas protegidas criadas no país naquela época, ainda hoje, reveste-se de certa pertinência quando consideramos a realidade de alguns parques brasileiros. Problemas fundiários, insuficiência de recursos financeiros e de pessoal, ainda muito comuns atualmente, acabam comprometendo, assim, o alcance dos objetivos parque (conservação da biodiversidade, uso público, educação ambiental) e a construção de processos de governança mais integrados e alinhados à dinâmica dos territórios que permeiam seu entorno.

Em 1981, o Instituto Brasileiro de Desenvolvimento Florestal - IBDF, por meio da Delegacia Estadual em Minas Gerais, criou uma comissão para estudar a viabilidade de se transformar o Parque Estadual da Serra do Cipó em Parque Nacional, estratégia encontrada, à época, para se tentar garantir a concretização de seu processo de implantação. Essa Comissão "realizou contato com instituições e pessoas ligadas ao assunto, levantou material bibliográfico sobre a área e visitou o local, resultando em proposta de criação do Parque Nacional da Serra do Cipó (IBAMA, 1994, p. 18).

Ainda segundo o ICMBio (2009), outra tarefa dessa comissão consistiu em adquirir "amigavelmente" o maior número das terras que viriam a compor o Parque Nacional, com o intuito de se reduzir futuros conflitos fundiários. Para tanto, dois funcionários do CETEC, em convênio com o IBDF, realizaram expedições pela serra para realizar demarcações de área, informar os moradores sobre a criação do parque, levantar limites e benfeitorias de propriedades e de posses passíveis de indenização. E assim, na data de criação do Parque Nacional da Serra do Cipó, em 25 de setembro de 1984 (Decreto n. 90.223), mais de 40\% da área (14.400 ha de 33.800 ha) já haviam sido legalmente adquiridos pelo governo federal. Para a época, este trabalho prévio de aquisição direta das áreas a serem incorporadas ao 
território do parque representou um fato inédito no cenário brasileiro, conforme relato de um dos analistas ambientais mais antigos do PARNASC.

Evidentemente, cabe refletir sobre essa postura pretensamente "amigável" no processo de aquisição das terras, referenciada no plano de manejo do parque. Segundo entrevistas com moradores antigos da Serra do Cipó, naquela época, não houve qualquer iniciativa no sentido de se promover uma aproximação, mobilização ou mesmo um debate com a população sobre o processo de criação do Parque. As pessoas eram comunicadas de sua criação e que teriam que vender suas propriedades.

Como já destacado, nesse momento, vigorava no Brasil o regime de ditadura militar que, em muito, justifica a postura assumida pelo Estado quando da criação do PARNASC. A força do poder ortodoxo do Estado, nesse caso, se sobrepôs a outros interesses e modos de vida ali existentes, fazendo valer os interesses do governo federal. Nas falas de alguns moradores antigos da Serra tal observação fica transparecida:

"Não falaram sobre os motivos para a criação do parque. Só disseram: vamos contar suas plantas, casa, terras..".

(ex-proprietário de terras da região de João Fernandes).

"Ia nas casas, conversava... falavam que ia criar. 'Inventou'!!!

Aí mediram a terra, contava os animais...as plantas....".

(ex-proprietário de terras da região das cachoeiras do Gavião, Andorinha e Tombador).

"Teve reunião do IBAMA para avisar os moradores e dizer que iria virar parque e que os moradores seriam desapropriados...".

(ex-proprietária da região das
"Bandeirinhas")

"Conversaram... disseram que ia montar o parque... la falar o que? 0 governo que estava fazendo!" 
"Diz que ia montar o parque e pronto! Não tinha acordo...não fazia acordo nenhum..."

(ex-proprietário da região de "Areias")

"Foi "inventado" !!! Isso aqui nunca foi parque! Só tinha lavoura...

IBAMA foi dobrando os moradores e tomando as terras..."

(moradora do Retiro)

"Pediram para legalizar a terra para poder receber. Muitos não conseguiram e ficou por isso mesmo. (...) um tal de José Maria chegou e disse: olha, nós vamos fazer negócio aqui. Quem tem gado, tem 90 dias para tirar. Depois disso, vamos matar o gado e chamar o dono para comer o churrasco. Falei que precisava apenas de 30 dias e que não tinha esse negócio de churrasco não"!

(ex-proprietário de terras da região das Bandeirinhas/Currais)

Além disso, muitos entrevistados afirmaram desconhecer os motivos da criação do parque, os critérios adotados para isso, à época, e como foram definidos os limites dessa área protegida. Apenas dois entrevistados mencionaram "imaginar" quais seriam esses motivos:

"Criaram o parque pra reservar mata, criar bicho...preservar..."

(ex-proprietário de terras da região das cachoeiras do Gavião, Andorinha e Tombador).

"Só pra criar bicho..."

(ex-proprietário da região de "Areias")

Diante dessa realidade, optamos por mencionar no título deste tópico a expressão "inventaram o parque", muito presente em nossos diálogos com moradores antigos da Serra do Cipó e que parece simbolizar, com exatidão, como foi conduzido o processo de criação do Parque Estadual da Serra do Cipó e sua posterior federalização: ancorado em uma concepção externa de proteção ambiental, concretizada "de cima para baixo" e alheia (ou pouco sensível) aos interesses e opiniões dos habitantes da região. 
Interessante destacar também que, segundo os relatos de moradores antigos da Serra do Cipó, apesar da postura "intransigente" do Estado, não eclodiram, à época, conflitos associados à criação do parque. Nos chamou a atenção as várias menções ao "respeito" existente por parte dos moradores em relação ao Estado:

\begin{abstract}
"A gente respeita a lei... se diz que é parque, respeitamos".
"Não houve [conflito]... não tinha essa opção...saí! "temos uma educação tamanha que sabemos respeitar todos.... e não foi o que recebemos".

(ex-proprietário de terras da região de João Fernandes).
\end{abstract}

\begin{abstract}
"Somente avisaram que iria virar parque... Os moradores aceitaram a decisão...". "Pessoal avisou que não poderia continuar... Não houve violência nem possibilidade de acordo para permanecer...".

(ex-proprietária de terras da região das "Bandeirinhas")
\end{abstract}

"Falou que é Federal, todo mundo obedece, não tem o que fazer!"

(ex-proprietário de terras da região das Bandeirinhas/Currais)

Podemos inferir, nesses casos, que o contexto de ditadura militar que vigorava no país foi, em grande medida, responsável por essa postura de "respeito", que também pode ser interpretada como "medo" de retaliações mais severas por parte do Estado.

Quando da federalização, o parque ainda não possuía nenhuma estrutura, contando apenas com um fiscal, José Moreira, vulgarmente conhecido como "Moreirão". Segundo dados de entrevista com um dos analistas ambientais mais antigos do PARNASC, Moreirão chegou à região com o desafio de garantir a implementação do parque, com prioridade para a proteção. Para tanto, assumiu uma postura rígida, que se resumia à fiscalização e ao combate, via aplicação de embargos e multas, de atividades como retirada de madeira para construção de casas, comercialização e produção de carvão (a partir de espécies sucupira branca, o pau monjolo), plantações e uso do fogo, muito comuns naquela época. Essa 
postura "rígida" do fiscal lhe garantiu o apelido de "mão branca" e acabou inaugurando uma imagem essencialmente repressora e punitiva do órgão ambiental na região, percebida ainda hoje em diálogos com alguns moradores da Serra do Cipó. Até então, o sentido de ordenamento priorizado não incorporou qualquer iniciativa voltada ao planejamento e gestão territorial com enfoque democrático e participativo.

Em 1987, com a publicação do Decreto n. 94.984 de 30/09/87, teve início o processo de desapropriação das terras que ainda não haviam sido adquiridas até então. Naquele momento, mudanças na legislação já não permitiam que o governo federal comprasse terras de posseiros (sem escritura), o que significou que muitos moradores tiveram "direito" apenas à indenização por benfeitorias, plantações e criações existentes. $\mathrm{O}$ baixo valor das indenizações resultou, dessa maneira, no pagamento de valores irrisórios, se considerados o tamanho das áreas inicialmente ocupadas, fato que comprometeu a continuidade dos exercícios de territorialidade de muitas famílias desapropriadas. Isso porque, sem dinheiro suficiente para comprar novas áreas, essas pessoas tiveram que abandonar seus modos de vida tradicionais e buscar outras formas de se sustentar, na maioria dos casos, enquanto empregados de outras fazendas ou em estabelecimentos comerciais locais.

Além dessas situações, existem aqueles moradores que alegam não ter recebido qualquer valor indenizatório até o presente momento (mesmo aqueles referentes apenas às benfeitorias), configurando um conflito fundiário que vem se arrastando ao longo dos anos. Nesse sentido, existem diferentes e contraditórios pontos de vista sobre a real situação fundiária do parque, motivados, sobretudo, pela ausência e desencontro de informações sobre esse assunto.

Ao analisarmos a postura do órgão ambiental na condução dos processos de criação e de regularização fundiária do PARNASC, fica evidente que o poder e os interesses do Estado, detentor do capital simbólico legitimado pela justiça e pelas leis, se sobrepôs aos demais interesses e direitos territoriais envolvidos. Não houve aí a possibilidade de se contestar ou pelo menos de se debater qual seria a categoria de área protegida mais adequada àquela realidade socioespacial. Com a publicação do decreto de criação do Parque, os moradores não tiveram outra alternativa que não a de tentar se enquadrar nos marcos legais vigentes à época, para tentar receber os valores indenizatórios. Tal postura por parte do órgão 
ambiental fica transparecida (e ganha contornos oficiais, a propósito) no trecho do plano de manejo do PARNASC, a seguir:

Durante o tempo decorrido entre 1987 e o presente, alguns proprietários não apresentaram documentação que comprovasse a condição de sua propriedade como regular e devidamente registrada, de modo a se habilitarem [grifo nosso] ao recebimento de indenização. Todos estes proprietários tiveram a oportunidade de vender suas terras [grifo nosso], ainda que fossem apenas posses, antes de 1984. Alguns decidiram não fazê-lo por entenderem que não era bom negócio (ICMBIO, 2009, p. 314).

Assim, aqueles "não habilitados" a receber as indenizações, por serem posseiros ou não terem benfeitorias em suas propriedades, tiveram suas terras classificadas como devolutas, um bem do Estado brasileiro. Além do comprometimento dos direitos territoriais desses moradores em permanecer em suas áreas e manter seus exercícios de territorialidade, atualmente, alguns ex-moradores continuam a alegar não terem recebido indenizações, apesar de terem deixado suas propriedades há mais de 30 anos. Atualmente, esses processos encontram-se judicializados e sem previsão de desfecho. Essa condição de "injustiça ambiental" (ACSELRAD, 2008) acabou comprometendo diretamente a possibilidade dessas pessoas de se reterritorializarem em outras áreas e, assim, manterem seus modos de vida e práticas i-materiais, mesmo que sob novas condições, o que gerou tensões, conflitos e situações de revolta que, até hoje, repercutem negativamente e prejudicam a imagem do órgão ambiental na região e, consequentemente, sua relação com as comunidades situadas no entorno do PARNASC.

\section{Considerações finais}

As pesquisas sobre o processo de criação do Parque Estadual da Serra do Cipó e sua subsequente federalização evidenciaram uma vinculação direta a interesses e olhares predominantemente externos à realidade da região, então filiados a reivindicações de 
cientistas e ambientalistas. Ao mesmo tempo, prevaleceu naquele momento uma ordem de proteção da natureza ancorada na perspectiva preservacionista, referenciada em modelos também exógenos, cujas influências foram marcantes na política ambiental do país naquele período. Como resultado, o viés de ordenamento predominante à época caracterizou-se pela forte presença do Estado Territorial, responsável por centralizar as decisões sobre os rumos da implantação, planejamento e gestão das áreas protegidas no país.

A adoção de uma postura distanciada e pouco aberta ao diálogo por parte do órgão ambiental resultou na sobreposição e em choques com exercícios de territorialidade préexistentes, com prevalência evidente da territorialidade do Estado. A imposição de uma lógica unidirecional e unilateral de proteção, ancorada no impedimento da permanência de núcleos populacionais, acarretou em muitos processos de desterritorialização. Muitos dos pequenos proprietários de terras, então carentes de capital simbólico para reivindicar/lutar por seus direitos territoriais, sofreram as interferências mais drásticas em suas formas de reprodução socioespacial. Inclusive, quando da ciência sobre a criação do parque e da impossibilidade de permanecerem em suas terras, prevaleceu aí, na visão desses interlocutores locais, o poder e a visão de proteção do Estado, à época, inquestionáveis. Como consequência, alguns dos moradores da região acabaram deixando suas propriedades antes mesmo de receber as indenizações a que tinham direito, se encontrando, portanto, impossibilitados de se reterritorializar e dar continuidade a seus modos de vida, mesmo que sob novas condições.

É preciso reconhecer que, ainda hoje, em muitas situações de criação de áreas protegidas, a condução desse processo ainda se encontra muito centralizada na figura do Estado e condicionada às decisões e linhas de pensamento dos órgãos de meio ambiente. Mesmo que atualmente já se perceba avanços significativos em termos de maior participação social - representada, por exemplo, pela obrigatoriedade da realização de consultas públicas -, são raros os casos em que se coloca em debate, junto às populações locais, qual seria a categoria mais adequada à realidade e modos de vida diretamente afetados pela proposta de criação de uma área protegida. No caso da criação de áreas de proteção integral, como os parques, o direito de escolha e os modos de vida desses grupos e sujeitos sociais acabam sendo prejudicados pelo ordenamento territorial que aí se substantiva, comprometendo 
assim seu "direito de autonomia para a decisão sobre seu próprio destino" (Escobar, 2005 apud Zhouri e Laschefski, 2010, p. 13).

Em decorrência disso, os rumos e os efeitos do ordenamento territorial via áreas protegidas tem sido acompanhados de intensos debates, tensões e conflitos, sobretudo quando se considera as implicações sobre as populações residentes no interior ou entorno dessas áreas. Nesse sentido, avançar nesta discussão exigiria se refletir criticamente sobre sua capacidade em contribuir para a "administração da des-ordem", como bem sugere Haesbaert (2006). Isso significa considerar o potencial dos parques enquanto instrumento de promoção de inclusão socioespacial e de melhores condições de vida para as populações locais, traduzidos, por exemplo, no incentivo a projetos conservacionistas, capazes de garantir a manutenção das formas de uso e apropriação que essas comunidades estabelecem no território, valorizando assim seus modos de vida e, ao mesmo tempo, contribuindo para o alcance dos objetivos das áreas de proteção. Outro desafio nessa direção sugere considerar o papel dos parques na efetiva construção e consolidação de processos de governança mais democráticos e inclusivos, capazes de ampliar o sentido de participação cidadã e de envolver um maior número de representatividades sociais nos processos decisórios, sejam esses concernentes à criação de áreas protegidas como também à gestão desses territórios.

Quando nos atemos ao exemplo do Parque Nacional da Serra do Cipó, criado em 1984, sua representatividade regional supervaloriza seu papel no fortalecimento do planejamento e da gestão territorial da Serra do Cipó. Não estamos nos referindo ao simples cumprimento de metas de conservação ou de uma quase obrigatoriedade, em tempos atuais, de se conferir um "tom eco" aos conteúdos de planejamento. Na verdade, o parque constitui um rico patrimônio paisagístico e cultural, um ativo territorial que efetivamente garante qualidade ao território, em termos de prestação de serviços ambientais à população residente em seu entorno direto (como preservação de nascentes e manutenção da qualidade da água, controle dos níveis de poluição, conservação de florestas, combate à caça de animais silvestres, entre outros). Ao mesmo tempo, a existência de uma unidade de conservação como o PARNASC vem contribuindo à promoção do equilíbrio e normatização dos diversos usos e interesses aí incidentes (como turismo, agricultura, pesquisa científica, 
proteção de atributos naturais, entre outros), num sentido de compatibilização de objetivos voltados à conservação da biodiversidade e ao desenvolvimento socioambiental. Portanto, o parque influi diretamente no nível de bem estar daqueles que ali vivem e na manutenção dos processos ecológicos e, também, de processos econômicos e socioculturais da Serra do Cipó.

\section{Referências bibliográficas}

ACSELRAD, Henri (org.). O que é justiça ambiental. Rio de Janeiro: Garamond, 2008. ISBN: 978-85-761-7159-1.

ACSELRAD, Henri. Sentidos da sustentabilidade urbana. In ACSELRAD, H. (Org.). A duração das cidades: sustentabilidade e risco nas políticas urbanas. Rio de Janeiro: DP\&A, 2001. p. 27-55

BECKER, Bertha K. Amazônia: mudanças estruturais e tendências na passagem do milênio. In MENDES, Armando Dias (org.). Amazônia, terra e civilização: uma trajetória de 60 anos. 2a ed. rev. aum. - Belém: Banco da Amazônia, 2005. p. 115-140.

CETEC - Fundação Centro Tecnológico de Minas Gerais. Relatório - Principais Atividades realizadas para a Implantação do Parque Estadual da Serra do Cipó. Belo Horizonte, agosto de 1982.

CORREA, Rosa L. T. \& GUIRAUD, , Luciene. Possibilidades e Limites de histórias de vida por meio de depoimentos orais na história da formação de professores. Revista Diálogo Educ., set/dez. 2009, vol. 9, n. 28, p. 671-678.

DEUS, José A. S., RODRIGUES, Ludmila \& GOULART, Viviane. Geologia e sociedade: uma problematização sobre a implantação de hidrelétricas e a respeito do papel da sociedade civil brasileira no processo de desenvolvimento sob a ótica do ordenamento territorial. In ? QUINTA-FERREIRA, M., BARATA, M. T., LOPES, F. C., ANDRADE, A. I., HENRIQUES, M. H., PENA DOS REIS, R. \& IVO ALVES, E. Para desenvolver a terra: Memórias e notícias de geociências no espaço lusófono. Imprensa Universitária de Coimbra, 2012.

HAESBAERT, Rogério. Ordenamento Territorial. Boletim Goiano de Geografia, março 2006, n. 1, (26), p. 117124.

HAESBAERT, Rogério. O Mito da Desterritorialização: do fim dos territórios à multiterritorialidade. 7a edição. Rio de Janeiro: Bertrand Brasil, 2004. ISBN: 978-85-286-1061-1.

IBAMA. Plano de Ação Emergencial do Parque Nacional da Serra do Cipó. Consultor Responsável: Geraldo Wilson Fernandes. Belo Horizonte, 1994.

ICMBIO. Plano de Manejo do Parque Nacional da Serra do Cipó e Área de Proteção Ambiental Morro da Pedreira: encartes 1, 2 e 3, 2009.

MEDEIROS, Rodrigo. A proteção da natureza: das estratégias internacionais e nacionais às demandas locais. Rio de Janeiro: UFRJ/PPGG, 2003. 391p. Tese (Doutorado em Geografia)

MEDEIROS, Rodrigo.; IRVING, Marta. A.; GARAY, Irene. Áreas Protegidas no Brasil: interpretando o contexto histórico para pensar a inclusão social. In IRVING, Marta. A. (org..) Áreas Protegidas e Inclusão Social. Construindo Novos Significados. Rio de Janeiro: Fundação Bio-Rio. Núcleo de Produção Editorial Aquarius, 2006. ISBN: 85-89291-10-3.

MELO, Josandra A. B. de. Ordenamento territorial e sustentabilidade: um diálogo possível? Revista Caminhos de Geografia, março/2010, v. 11, n. 33, p. 220-229. 
MOREIRA, Ruy. O espaço e o contra-espaço: as dimensões territoriais da sociedade civil e do Estado, do privado e do público na ordem espacial burguesa. In SANTOS, Milton e BECKER, Berta. (orgs.) Território, Territórios: ensaios sobre o ordenamento territorial Rio de Janeiro, DP\&A, 2a edição, 2006. ISBN: 978-8598271-42-2.

PERES, Renata B. e CHIQUITO, Elisângela. Ordenamento territorial, meio ambiente e desenvolvimento regional: novas questões, possíveis articulações. R. B. ESTUDOS URBANOS E REGIONAIS, Novembro 2012, vol.14, n.2, p. 71-86. DOI: http://dx.doi.org/10.22296/2317-1529.2012v14n2p71

SANCHO, Altair e DEUS, J. Áreas Protegidas e Ambientes Urbanos: novos significados e transformações associados ao fenômeno da urbanização extensiva. Revista Soc. \& Nat., vol 27, n. 2, mai-ago, 2015, p. 223-238. DOI: http://dx.doi.org/10.1590/1982-451320150203

SANTA INEZ, J. R. M. Planejamento territorial intermunicipal: uma proposta para sua instrumentalização. Revista Integração, ano X, no 36, jan-mar, 2004, p.17-25.

SANTANA, Arthur B. A BR-163: "ocupar para não entregar", a política da ditadura militar para a ocupação do “vazio” Amazônico. ANPUH - XXV SIMPÓSIO NACIONAL DE HISTÓRIA - Fortaleza, 2009.

SANTOS, Milton e BECKER, Berta. (orgs.) Território, Territórios: ensaios sobre o ordenamento territorial Rio de Janeiro, DP\&A, 2a edição, 2006. ISBN: 978-85-982-7142-2.

SANTOS, Milton. Técnica, espaço, tempo: globalização e meio técnico-científico-informacional, SP: Hucitec: 1994. ISBN: 978-85-314-1049-9.

ZHOURI, A. e LASCHEFSKI, K. Desenvolvimento e Conflitos Ambientais. Belo Horizonte: editora da UFMG, 2010. ISBN: 978-85-704-1774-9. 